\title{
Effects of exposure to hypoxia on the signal-averaged electrocardiogram in healthy subjects
}

\author{
F. Roche, J.-C. Barthélémy, R. Adamec*, A. Geyssant and J.-R. Lacour $\dagger$ \\ University Hospital and Laboratoire de Physiologie, GIP Exercise, Saint-Etienne, France; *University Hospital, \\ Geneva, Switzerland; †University Hospital \& Laboratoire de Physiologie, Lyon, France
}

KEY WORDS: Signal-averaged electrocardiogram, normobaric hypoxia, ventricular late potentials.

The effects of hypoxia on the signal-averaged ECG (SAECG) were investigated in 26 healthy active subjects with no suggestion of cardiac disease. The SAECG was recorded in each resting subject in normoxic and hypoxic normobaric conditions (inspired $\mathrm{O}_{2}$ fraction $20.7 \mathrm{vs} \mathrm{10.0 \% )} \mathrm{which} \mathrm{lowered} \mathrm{resting} \mathrm{arterial} \mathrm{O}_{2}$ saturation from $98.6 \pm 0.6 \%$ to $77.7 \pm 8 \%$. Recordings from four subjects (three men) met the definition of abnormal late potentials at baseline; in all these subjects but one, who exhibited an improved but still abnormal $Q R S$ duration, these parameters returned to normal in hypoxic conditions. The duration of the filtered QRS was significantly reduced (from 107.6 \pm 13.2 to $101.6 \pm 11.3 \mathrm{~ms}, \mathrm{P}<0.01$ ), the duration of the low amplitude signals in the terminal portion of the $Q R S<40 \mu V(L A S)$ significantly decreased (from $26.5 \pm 9.5$ to $22.7 \pm 7.9 \mathrm{~ms}, \mathrm{P}<0.05$ ) and the root mean square voltage in the last $40 \mathrm{~ms}$ (Term-RMS) increased non-significantly (from $55.8 \pm 40.2$ to $69 \cdot 1 \pm 38.3 \mu \mathrm{V}, \mathrm{P}=0.058$ ). Hypoxia determined a higher $(\mathrm{P}<0.05)$ heart rate increase in subjects with abnormal records than in normal subjects.

These data could be related to a sympathic discharge. They suggest that: (1) variation in heart rate could affect the SAECG; (2) exposure to hypoxia improves SAECG parameters in healthy subjects, possibly related to sympathetic discharge; (3) abnormal records collected during sinus bradycardia could represent a type of false-positive expression of late potentials in young active adults.

\section{Introduction}

Low amplitude late potentials detected by the signal averaged electrocardiogram (SAECG) in the terminal part of ventricular activation are considered as an important non-invasive indicator, identifying patients with previous myocardial infarction at risk for ventricular tachycardia and sudden cardiac death ${ }^{[1-9]}$. The anatomical changes due to myocardial infarction determines a slow and inhomogeneous activation around the scarred area, which may be the site where reentry may occur $^{[10]}$.

Some papers have focused on the analysis of ventricular late potentials in normal subjects ${ }^{[11-13]}$ in order to establish the criteria that will be used as cut-off limits of normal reference values. The incidence of abnormal signals in normal subjects is low and has been reported from $0 \%$ to $7 \% \%^{[14]}$. It is unclear whether the presence of late potentials in asymptomatic individuals without evident structural heart disease has prognostic implications. Hypoxia determines various but limited electrocardiogram (ECG) abnormalities at extreme altitudes in normal subjects ${ }^{[15-17]}$. However, ECG occasionally show premature ventricular beats in healthy subjects in these conditions ${ }^{[1]}$.

The purpose of the study was to examine whether acute exposure to normobaric hypoxia is associated with

Revision submitted 18 August 1994, and accepted 26 August 1994.

Correspondence: F. Roche, MD, Exploration Fonetionnelle, Centre Hospitalier et Universitaire Nord-Niveau 6, F-42055 Saint-Etienne Cedex 2, France. a change in the signal averaged electrocardiogram in normal subjects.

\section{Methods}

STUDY GROUP

Twenty-six healthy, young volunteer medical residents were studied (16 men, 10 women). Their mean age was $20.8 \pm 2.2$ (mean \pm standard deviation). None had an history of heart (chest pain, syncope, sudden death in the family) or metabolic disease or systemic hypertension. The characteristics of the study group are listed in Table 1.

None was on any medication or was a professional athlete. Their physical examination and standard 12lead electrocardiogram (ECG) was normal. There was no statistical difference between the two groups, with or without criteria as regards late potentials, age, weight, height, or gender.

\section{SIGNAL-A VERAGED ELECTROCARDIOGRAM}

Signal averaged data were recorded on a commercially available system (Corazonics Predictor II) using Simson's method ${ }^{[11]}$. The skin was cleaned with alcohol and abraded before standard orthogonal bipolar X, Y and $Z$ leads were placed. At least 200 beats were averaged to obtain noise levels equal to, or less than, $0.7 \mu \mathrm{V}$. Signals were amplified and filtered using a bidirectional Butterworth 40 to $250 \mathrm{~Hz}$ band pass filter. 
Table 1 Characteristics of the study group

\begin{tabular}{lc}
\hline Sex (men/women) & $16 / 10$ \\
Age (years) & $20 \cdot 81 \pm 2 \cdot 23$ \\
Height $(\mathrm{cm})$ & $170 \cdot 30 \pm 8 \cdot 72$ \\
Weight $(\mathrm{kg})$ & $65 \cdot 38 \pm 11 \cdot 37$ \\
Maximal $\mathrm{O}_{2}$ uptake $\left(\mathrm{ml} \mathrm{kg}^{-1} . \mathrm{min}^{-1}\right)$ & $51 \cdot 51 \pm 7 \cdot 69$ \\
Arterial $\mathrm{O}_{2}$ Saturation $(\%)$ in normoxia & $98 \cdot 29 \pm 0 \cdot 75$ \\
Arterial $\mathrm{O}_{2}$ Saturation $(\%)$ in hypoxia & $77 \cdot 71 \pm 8 \cdot 04$ \\
\hline
\end{tabular}

Signal-averaged parameters of the filtered QRS duration, duration of signals less than $40 \mu \mathrm{V}$ in the terminal part of the QRS (LAS) and the root mean squared voltage in the terminal $40 \mathrm{~ms}$ (Term-RMS) were analysed.

The presence of late potentials was defined according to the Task Force Committee recommendations ${ }^{[14]}$. (1) Filtered QRS duration $>114 \mathrm{~ms}$; (2) Term-RMS $<20 \mu \mathrm{V}$; (3) LAS $>38 \mathrm{~ms}$. These values were used as criteria to define two groups: normal (VLP - ) and abnormal (VLP+) subjects as recorded in normoxic conditions. Abnormal subjects were defined as having at least two abnormal values.

\section{ENVIRONMENTAL CONDITIONS}

After being fully informed of the nature of the study and after giving consent, the 26 native subjects, who were resting at sea level $(\mathrm{PB}=723 \mathrm{Torr})$ were recorded, both in normoxic normobaric (inspired oxygen concentration $=20.7 \%$ ) and in hypoxic normobaric conditions (inspired oxygen concentration $=10 \cdot 0 \%$ ). Inhalation of a gas mixture with a low oxygen content for $15 \mathrm{~min}$ lowered arterial $\mathrm{O}_{2}$ saturation to $77.7 \pm 8.0 \%$; this is equivalent to being at an altitude of $5700 \mathrm{~m}$. Oxygen haemoglobin saturation was monitored using a pulse oximeter (Datex, Finland) ${ }^{[18]}$. Two SAECG recordings (in normoxia and hypoxia) were performed consecutively on each patient using similar positions of both body and electrode.

\section{STATISTICAL ANALYSIS}

Data were analysed using Student's paired and unpaired t-test. Statistical significance was defined as $P<0.05$. Data in text and tables are expressed as mean \pm 1 standard deviation $(m \pm S D)$.

\section{Results}

Abnormal late potentials (VLP+) were recorded under normoxic environmental conditions, in four subjects (three men, one woman). The value was reached following the criteria mentioned above ${ }^{[14]}$. Under normoxic conditions, the two groups showed a significant statistical difference as regards QRS duration, TermRMS, LAS and heart rate (Table 2). Under similar conditions, in three other subjects the QRS duration was abnormal only in that its standard cut-off was $114 \mathrm{~ms}$; a fourth subject presented only an abnormal Term-RMS. The number of averaged cycles and the noise level were not statistically different under conditions either normoxic or hypoxic (Table 3).

\section{RELATIONSHIP BETWEEN CRITERIA OF VLP}

Among the normoxic and hypoxic data there was a significant positive linear relationship between QRS duration and LAS $(P<0 \cdot 001)$, and a significant negative linear relationship between QRS duration and TermRMS $(P<0.001)$ (Fig. 1). LAS and Term-RMS were also negatively correlated (Fig. 2).

\section{EFFECT OF HYPOXIA}

Signal-averaged ECG (SAECG) parameters recorded in the two described conditions, normoxia and hypoxia, are listed in Table 3. A low noise level $(<0.7 \mu \mathrm{V})$ was easily obtained under hypoxic conditions. Significant statistical differences between the SAECG parameters were observed between normoxia and hypoxia; however, hypoxic conditions determined a move towards a better

Table 2 Changes in the signal-averaged electrocardiogram in the two groups (LAS, duration of the low amplitude signals in the terminal part of the QRS in which voltage is $S 40 \mu$ volts: Term-RMS. root mean square voltage in the last $40 \mathrm{~ms}$ of the $Q R S, V L P$, ventricular late potentials)

\begin{tabular}{|c|c|c|c|c|}
\hline & & VLP $-(n=22)$ & VLP+ $(n=4)$ & $P$ value \\
\hline \multirow[t]{2}{*}{ QRS duration (ms) } & Normoxia & $104 \cdot 1 \pm 11 \cdot 1$ & $126 \cdot 4 \pm 4 \cdot 7$ & $<0.001$ \\
\hline & Hypoxia & $100 \cdot 7 \pm 11 \cdot 5^{*}$ & $106 \cdot 0 \pm 10 \cdot 3^{* *}$ & ns \\
\hline \multirow{2}{*}{ LAS (ms) } & Normoxia & $23 \cdot 2 \pm 5 \cdot 6$ & $44 \cdot 5 \pm 4 \cdot 5$ & $<0-01$ \\
\hline & Hypoxia & $20 \cdot 8 \pm 7 \cdot 1^{*}$ & $32 \cdot 9 \pm 2 \cdot 5^{* *}$ & $<0.05$ \\
\hline \multirow[t]{2}{*}{ Term-RMS $(\mu \mathrm{V})$} & Normoxia & $63 \cdot 9 \pm 38 \cdot 3$ & $113 \pm 6.8$ & $<0.05$ \\
\hline & Hypoxia & $74 \cdot 7 \pm 38 \cdot 8^{*}$ & $38 \cdot 3 \pm 14 \cdot 4^{* *}$ & ns \\
\hline \multirow[t]{2}{*}{ Heart rate (beats. $\min ^{-1}$ ) } & Normoxia & $65 \cdot 2 \pm 13 \cdot 7$ & $48 \cdot 2 \pm 5 \cdot 4$ & $<0.05$ \\
\hline & Hypoxia & $79.1 \pm 18^{* * * *}$ & $80 \cdot 5 \pm 14 \cdot 5^{* *}$ & ns \\
\hline
\end{tabular}

*Hypoxia vs normoxia $P=\mathrm{ns}$.

* Hypoxia vs normoxia $P<0-05$.

***Hypoxia vs normoxia $P<0.001$. 
Table 3 Changes in signal-averaged paramerers with hypoxia exposure in healthy subjects (LAS, duration of the low amplitude signals in the terminal part of $Q R S$ whose voltage is $\leq 40 \mu$ volts; Term-RMS, root mean square voltage in the last $40 \mathrm{~ms}$ of the $Q R S$ )

\begin{tabular}{lccc}
\hline & $\begin{array}{c}\text { Normoxia } \\
\mathrm{n}=26\end{array}$ & $\begin{array}{c}\text { Hypoxia } \\
\mathbf{n}=26\end{array}$ & $P$ value \\
\hline QRS duration (ms) & $107.56 \pm 13$ & $101 \cdot 58 \pm 11$ & $<0.01$ \\
LAS (ms) & $26.5 \pm 9 \cdot 5$ & $22 \cdot 7 \pm 7.9$ & $<0.05$ \\
Term-RMS $(\mu \mathrm{V})$ & $55 \cdot 8 \pm 40 \cdot 1$ & $69 \cdot 1 \pm 38.3$ & $\mathrm{~ns}$ \\
Heart rate (beats. min $\left.^{-1}\right)$ & $62.6 \pm 14$ & $79 \cdot 3 \pm 17$ & $<0.0001$ \\
Number of cycles & $320 \pm 78$ & $304 \pm 47$ & $\mathrm{~ns}$ \\
Noise $(\mu \mathrm{V})$ & $0.54 \pm 0.2$ & $0.59 \pm 0.2$ & $\mathrm{~ns}$ \\
\hline
\end{tabular}

global balance of the ECG as regards the three monitored parameters: QRS duration decreased from $107.6 \pm 13.2$ to $101.6 \pm 11.3(P<0.01)$, LAS fell from $26.5 \pm 9.5$ to $22.7 \pm 7.9(P<0.05)$, and Term-RMS increased from $55 \cdot 8 \pm 40 \cdot 2$ to $69 \cdot 1 \pm 38 \cdot 3, P=0 \cdot 058$. On the other hand, acute hypoxic exposure was associated with an increase in heart rate from $62 \cdot 6 \pm 14 \cdot 2$ to $79 \cdot 3 \pm 17 \cdot 3$ beats min $^{-1}$.

Under hypoxic conditions, all SAECG recordings were within normal limits, which means that abnormal values were normalized in all but two subjects, presenting a QRS duration exceeding $114 \mathrm{~ms}$ (118 and $119 \mathrm{~ms}$ ), the other parameters being normal. SAECG parameters in the two groups (VLP+ and VLP - ), recorded during both conditions, are summarized in Table 2 . Under hypoxic conditions, the differences between groups disappear as regards QRS duration, Term-RMS and heart rate; only LAS showed a statistical difference (20.8 $\pm 7 \cdot 1$ in VLP - vs $32.9 \pm 2.5 \mathrm{~ms}$ in VLP+, $P<0.05$ ).

\section{EFFECT OF HEART RATE}

Heart rate under normoxic conditions was significantly different between the two groups (VLP+, $48.2 \pm 5.4$ beats $\min ^{-1} ; \quad$ VLP -,$\quad 65.2 \pm 13.7$ beats $\left.\min ^{-1} ; P<0.05\right)$. The statistical difference disappeared under hypoxic conditions, due to a significantly

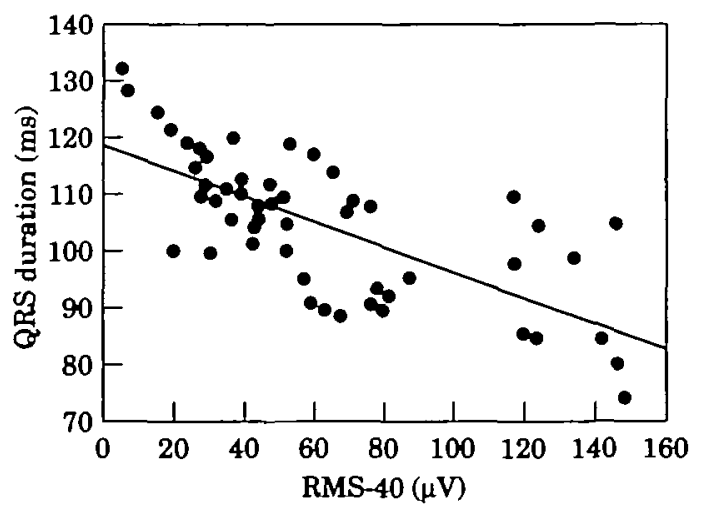

Figure 1 Linear correlation between QRS duration and rootmean-square voltage in the last $40 \mathrm{~ms}$ (RMS-40). $n=52 ; P<0.01$; $\mathrm{R}=0 \cdot 70$. larger increase in heart rate in the VLP+ group (Fig. 3). Hypoxia determined a statistically significant variation in the three criteria in the VLP+ group but not in the VLP - group (Table 2).

Taking the normoxic and hypoxic data as a whole, a significant linear relationship was found between, on the one hand, heart rate, and on the other, QRS duration and LAS.

\section{Discussion}

Late potentials detected by the SAECG are a potent non-invasive indicator of patients at risk for lethal arrhythmias ${ }^{[2,4,5,9,19]}$.

The population at risk is mainly represented by patients who suffered an earlier myocardial infarction. In this particular population, the mortality and ventricular tachycardia rate can reach $30 \%$ in 2 years when late potentials are present ${ }^{[20]}$; the lack of late potentials have a negative predictive value of more than $90 \%$. The data were then applied to the normal population, and demonstrated a percentage from $0 \%$ to $7 \%$ in a supposedly healthy young population. In our population, the observed percentage reached $15.4 \%$ (four subjects), which is more than in the previously published data ${ }^{[12,13,21]}$. No echocardiograms were performed, but the maximal treadmill exercise test was normal in our population,

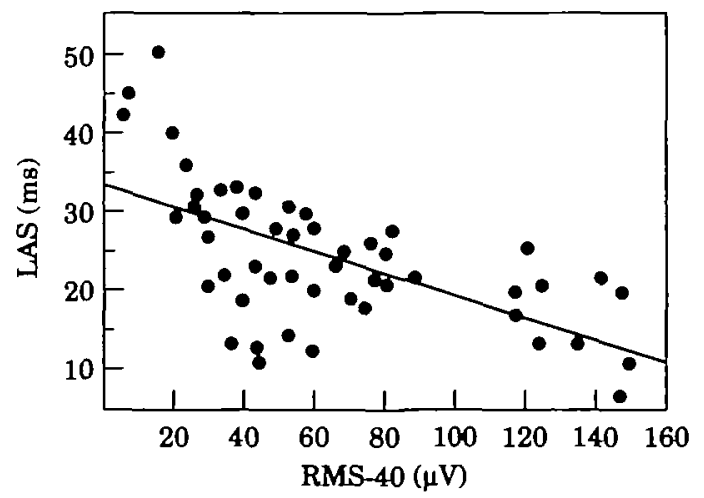

Figure 2 Linear correlation between low-amplitude signals in the terminal portion of the QRS complex $<40 \mu \mathrm{V}$ (LAS) and rootmean-square voltage in the last $40 \mathrm{~ms}$ (RMS-40). $n=52 ; P<0.01$; $\mathrm{R}=0-61$. 


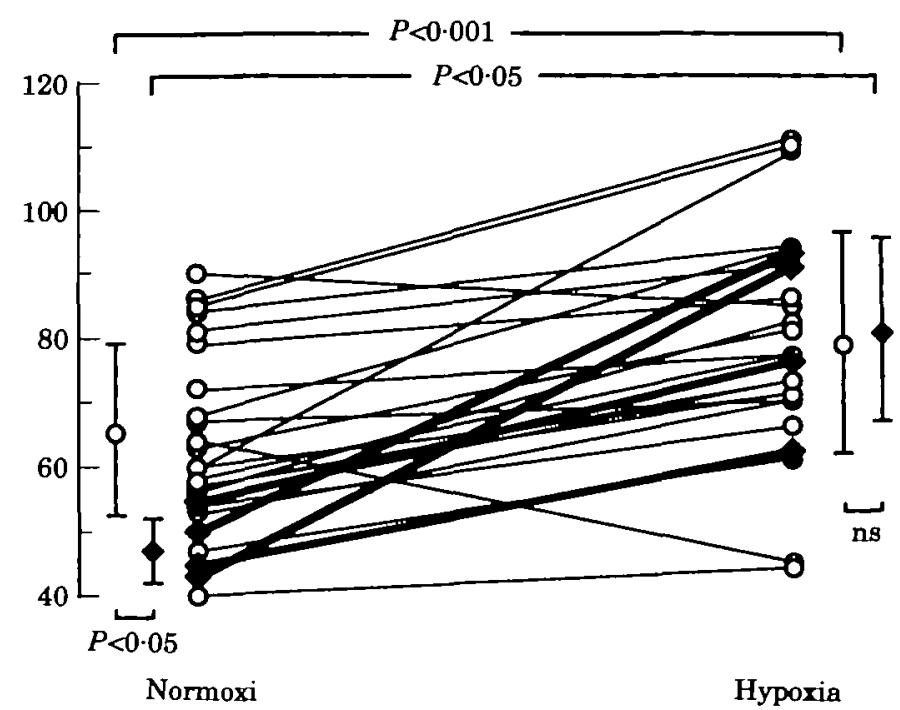

Figure 3 Increase in heart rate during hypoxia in normal subjects and with abnormal SAECG records. O $=\mathrm{VLP}-; \bullet=\mathrm{VLP}+$.

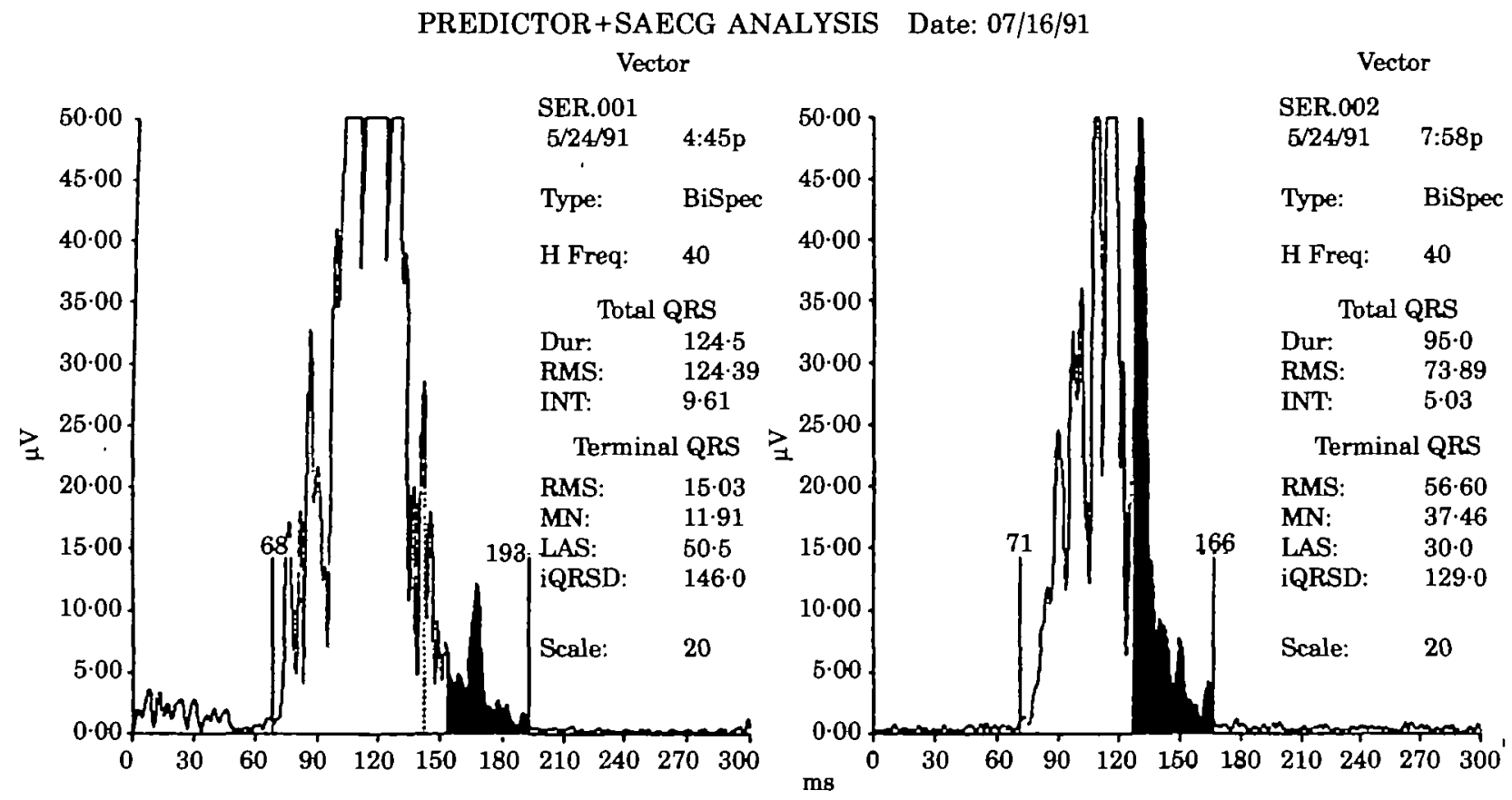

Figure 4 SAECG recorded in normoxic normobaric conditions (left) and in hypoxic normobaric conditions (right) in a young active subject with no cardiac disease.

including in those demonstrating an abnormal SAECG. Among the four abnormal recordings found under normoxic conditions, two of them could have been falsely classified due to the automatical calculation by the computer, based on the visual analysis of the QRS end-points; finally, the low noise level $(0.33$ and $0.60 \mu \mathrm{V})$ of these two recordings convinced us to consider them as abnormal. However, under hypoxic conditions, these four tracing are judged as normal. Thus hypoxia seems to normalize positive as well possibly false-positive tracings. Under hypoxic conditions, one of these subjects still had an isolated abnormality, an abnormal QRS duration. In the two subjects presenting a conclusive abnormal test during normoxia, the vector magnitude complexes were indistinguishable from those seen in patients demonstrating a spontaneous sustained ventricular tachycardia after myocardial infarction (Fig. 4).

The two abnormal tests were recorded in highly trained subjects; later, they demonstrated similar abnormalities. Smith also described normalization of abnormal SAECG parameters in highly trained athletes when 
running a marathon ${ }^{[22]}$. These two subjects presented an incomplete right bundle branch block under normoxic conditions, while QRS duration remained less than $120 \mathrm{~ms}$.

It is of note that less pronounced, but still significant, variations in SAECG parameters where observed when the analysis included only the normal group (VLP - ). A fixed number of QRS determined the end of the SAECG recordings (Table 3 ). This normalizes the noise level measurement. Furthermore, we found no significant difference in the noise level in the two conditions.

The risk to this supposed normal population is not yet established, but if present, this risk could be enhanced by exposure to specific external factors. Cardiac 'work' at height represents such a factor. It has been demonstrated that exercise enhanced cardiac desynchronization in the presence of coronary artery disease ${ }^{[23,24]}$; however, in normal subjects, resting desynchronization, if present, disappears when exercising. West ${ }^{[25]}$ showed that acute hypoxia determines an increase in cardiac output directly related to the observed increase in heart rate; the higher the altitude, the greater the increase in heart rate. Hypoxia represents an external stress factor similar to exercise for enhancing oxygen consumption and has been used to detect coronary artery disease ${ }^{[26,27]}$. This could explain the paradoxal observation of improvement of criteria of late potentials observed by Caref et al ${ }^{[28]}$ when recorded immediately after a stress test; in such conditions, the anticipated deterioration could be limited or even over-corrected by modifying potentials related to the increased heart rate. The same improvement in synchronization was observed in dogs where myocardial perfusion was improved during exercise, including in myocardial areas previously demonstrating poor conduction at rest ${ }^{[29]}$. This could be related to a sympathetic discharge. Hypoxia acts as a factor determining a sympathic discharge previously reported in acute hypoxia exposure ${ }^{[30-33]}$.

As suggested by Goldberger et al..$^{[34]}$, our data underline the fact that the SAECG does not measure 'fixed' parameters. Furthermore, these authors described a significant variation between the parameters, similar to ours: a shortened QRS duration, increased RMS voltage, fall in LAS duration, and physiological or pharmacological beta adrenergic stimulation; however, among the stimulations used by these authors, the variation measured after exercise was not significant, although being of the same magnitude. In this study, the heart rate was accelerated due to the different stimulations, as shown by the reported significant decrease in the RR intervals, a direct effect of beta adrenergic stimulation.

If exercise, or hypoxia, reduced the observed resting desynchronization, it could be assumed that the heart was normal. Conversely, in healthy people, an electrocardiogram recording at extreme altitude occasionally shows premature ventricular contractions associated with right bundle branch block, conduction disturbance, right ventricular hypertrophy, flattened $T$ waves and wave inversions ${ }^{[15]}$. All these changes return to control value at sea level. Karliner $e t$ al. concluded that transient ECG alteration in healthy subjects at extreme altitude are consistent with raised pulmonary pressure. In our subjects submitted to hypoxia, the observed diminution of QRS duration is the opposite of the installation of a bundle branch block ${ }^{[30-33]}$.

We think abnormalities observed in our population are false-positive since they do not correspond to a myocardial abnormality but to a resting slow intramyocardial conduction time. This is reinforced by the observation of continuous variation of, for example, QRS duration with heart rate. In a normal heart, we record the relative effects of the vagal and sympathic tone. The bradycardia observed in our 'positive' subjects underlines the effect of heart rate and vagal tone. The question whether the abnormalities corrected by hypoxia are abnormal or should be labelled as 'falsely' abnormal remains,

It would be better to redefine abnormality using heart rate as a cofactor; the normality could be defined for a given heart rate value - the slower the heart, the more permissive the criteria.

\section{Conclusion}

Our data underline the fact that the SAECG does not measure 'fixed' parameters. Exposure to hypoxia modifies the value of two of the three SAECG parameters in healthy normal young subjects. Baseline abnormal values were normalized by hypoxia; these subjects should probably be considered as normal even in the presence of baseline abnormal values. In this case, hypoxia appears as a factor determining an enhanced cardiac synchronization throughout a sympathic discharge.

Hypoxia, and the associated sinus tachycardia, lead to a shortening of QRS and LAS (and an increased RMS) in healthy subjects without ventricular late potentials, effects mediated through beta adrenergic stimulation.

Bradycardia could represent a state determining a false-positive expression of late ventricular potentials in young active subjects.

\section{References}

[1] Buxton AE, Simson MB, Fakone RA et al. Results of signal-averaged clectrocardiography and electrophysiologic study in patients with non sustained ventricular tachycardia after healing of acute myocardial infarction. Am J Cardiol 1987; 60: 80-5.

[2] Denes P, Santarelli P, Hauser RG, Uretz EF. Quantitative analysis of the high-frequency components of the terminal portion of the body surface QRS in normal subjects and in patients with ventricular tachycardia. Circulation 1983; 67: 1129-38.

[3] Freedman RA, Gillis AM, Keren A et al. Signal-averaged electrocardiographic late potentials in patients with ventricular fibrillation or ventricular tachycardia: correlation with clinical arrhythmia and electrophysiologic study. J Am Coll Cardiol 1985; 55: 1350-3. 
[4] Farrell TG, Bashir Y, Cripps T et al. Risk stratification for arrhythmic events in post infarction patients based on heart rate variability, ambulatory electrocardiographic variables and the signal-averaged electrocardiogram. J Am Coll Cardiol 1991; 18: 687-97.

[5] Kanovsky M, Falcone R, Dresden C et al. Identification of patients whth ventricular tachycardia after myocardial infarction: signal-averaged electrocardiogram, holter monitoring, and cardiac catheterization. Circulation 1984; 70: 264-70.

[6] Nalos PC, Gang ES, Mandel WJ et al. The signal-averaged electrocardiogram as a screening test for inducibility of sustained ventricular tachycardia in high risk patients: a prospective study. J Am Coll Cardiol 1987; 9: 539-48.

[7] Turitto G, Fontaine JM, Ursell SN et al. Value of the signal-averaged electrocardiogram as a predictor of the results of programmed stimulation in non sustained ventricular tachycardia. Am J Cardiol 1988; 61: 1272-8.

[8] Winters SL, Stewart D, Targonski A, Gomes A Role of signal averaging of the surface QRS complex in selecting patients with non sustained ventricular tachycardia and high grade ventricular arrhythmias for programmed ventricular stimulation. J Am Coll Cardiol 1988; 12: 1481-7.

[9] Gomes JA, Winters SL, Martinson $M$ et al. The prognostic significance of quantitative signal-averaged variables relative to clinical variables, site of myocardial infarction, ejection fraction and ventricular premature beats: a prospective study. J Am Coll Cardiol 1989; 13: 377-84.

[10] Gardner PJ, Ursell PC, Fenoglio JJ, Wit AL. Electrophysiologic and anatomic basis for fractionated electrocardiograms recorded from healed myocardial infarctions. Circulation 1985; 72: 596-611.

[11] Simson MB. Use of signals in the terminal QRS complex to identify patients with ventricular tachycardia after myocardial infarction. Circulation 1981; 64: 235-42.

[12] Coto H, Maldonato C, Palakurthy P, Flowers NC. Late potentials in normal subjects and in patients with ventricular tachycardia unrelated to myocardial infarction. Am J Cardiol 1985; 55: 384-90.

[13] Flowers NC, Wylds AC. Ventricular late potentials in normal subjects. Herz 1988; 13: 160-8.

[14] Breithardt G, Cain ME, El-Sherif $\mathrm{N}$ et al. Standard for analysis of ventricular late potentials using high-resolution or signal-averaged electrocardiography: a statement by the Task Force Committee of the European Society of Cardiology, the American Heart Association, and the American College of Cardiology. Circulation 1991; 83: 1481-88.

[15] Karliner JS, Sarnquist FF, Graber CJ et al. The electrocardiogram at extreme altitude: expenence on Mt Everest. Am Heart J 1985; 109: 505-13.

[16] Milledge JS. Electrocardiographic changes at high altitude. $\mathrm{Br}$ Heart J 1962; 25: 291-8.

[17] Cummings P, Lysgaard M. Cardiac arrhythmia at high altitude. Wesr J Med 1981; 135: 66-8.
[18] Barthélémy JC, Geyssant A, Riffat $\mathrm{J}$ et al. Aocuracy of pulse oxymetry during moderate exercise: a comparative study. Scand J Clin Lab Invest 1990; 50: 533-9.

[19] Denes P, Uretz E, Santarelli P. Determinants of arrhythmogenic ventricular activity detected on the body surface $Q R S$ in patients with coronary artery disease. Am J Cardiol 1984; 53: $1519-23$.

[20] El-Sherif N, Ursell SN, Fontaine G et al. Prognosis significance of signal-averaged electrocardiogram depends on the time of recording in the post-infarction period. Am Heart $J$ 1989; 118: 256-64.

[21] Raineri AA, Traina M, Rotolo A, Lombardo RM. Quantitative analysis of ventricular late potentials in healthy subjects. Am J Cardiol 1990; 66: 1359-62.

[22] Smith GS, Vacek JL, Wilson DB et al. Exercise-induced alterations of signal-averaged electrocardiograms in marathon runners. Am Heart J 1989; 118: 1198-1202.

[23] Righetti A, Barthélémy JC, Ratib O et al. Global and regional synchronicity of ventricular contraction during and following exercise. Circulation 1984; 70 (Suppl 11): 157.

[24] Righetti A, Barthélémy JC, Ratib O et al. Fonction ventriculaire globale et synchronicité de contraction pendant et après l'effort. Schweiz Med Wschr 1984; 114: 1607-11.

[25] West JB. High altitude medicine and physiology. London: Chapman and Hall, 1989.

[26] Leevy RL, Brueen HG, Russel HG. The use of electrocardiogram changes caused by induced anoxemia as a test for coronary insufficiency. Am J Med Sci 1939; 197: 241-6.

[27] Broch OJ. Calibrated hypoxemia test in normal subjects and coronary patients: hemodynamic and acid-base equilibrium in hypoxemia of short duration. Act Med Scand 1972; 191: 181.

[28] Caref EB, Goldberg N, Mendelson L et al. Effects of exercise on the signal-averaged electrocardiogram in coronary artery disease. Am J Cardiol 1990; 66: 54-8.

[29] Dawson AK, Leon AS, Taylor HL. Effect of submaximal exercise on vulnerability to fibrillation in canine ventricle. Circulation 1979; 60: 798-804

[30] Bubb WJ, Howley ET, Cox RH. Effects of various levels of hypoxia on plasma catecholamines at rest and during exercise. Aviat Space Environ Med 1983; 54: 637-40.

[31] Cunningham WL, Becker EJ, Kreuzer F. Catecholamins in plasma and urine at high altitude. J Appl Physiol 1965; 20: 607-10.

[32] Moncloa F, Gomez M, Hurtado A. Plasma catecholamines at high altitudes. J Appl Physiol 1965; 20: 1329-31.

[33) Maher JT, Manchanda SC, Cymerman A et al. Cardiovascular responsiveness to beta-adrenergic stimulation and blockage in chronic hypoxia. Am J Physiol 1975; 228: 477-81.

[34] Goldberger JJ, Ahmed MW, Parker MA, Kadish AH. Assessment of effects of autonomic stimulation and blockade on the signal-averaged electrocardiogram. Circulation 1994; 89: $1656-64$. 